\title{
Article
}

Mycosphere

\section{Favolus gracilisporus (Polyporaceae, Basidiomycota), an East Asian polypore species new to the European mycobiota}

\author{
Papp $V^{1}$ and Dima $B^{2,3}$
}

\author{
${ }^{1}$ Department of Botany, Faculty of Horticultural Science, Szent István University, H-1518, Pf. 53., Budapest, Hungary; \\ papp.viktor@kertk.szie.hu \\ ${ }^{2}$ Department of Plant Anatomy, Institute of Biology, Eötvös Loránd University, Pázmány Péter sétány 1/c, H-1117 \\ Budapest, Hungary; cortinarius1@gmail.com \\ ${ }^{3}$ Department of Biosciences (Plant Biology), Viikki Plant Science Centre, University of Helsinki, P. O. Box 65, FI-00014 \\ Helsinki, Finland; dima.balint@helsinki.fi
}

Papp V, Dima B 2017 - Favolus gracilisporus (Polyporaceae, Basidiomycota), an East Asian polypore species new to the European mycobiota. Mycosphere 8(6), 1177-1184, Doi 10.5943/mycosphere/8/6/7

\begin{abstract}
The interesting finding of Favolus gracilisporus a recently described polypore species from East Asia is reported new to the European mycobiota from Hungary (Central Europe). This species has previously been known only from the type locality, Mt Hagga in South Korea. The ITS sequence, macro-, microscopical characteristics and photographs of the Hungarian specimen are given.
\end{abstract}

Key words - Central Europe - new record - Polyporus - phylogeny

\section{Introduction}

Europe is probably the best investigated area regarding the polypore mycobiota with approx. 400 poroid species (Ryvarden \& Melo 2014). Nevertheless, new species (e.g. Caudicicola gracilis Kotir., Kulju \& Miettinen, Ceriporia pierii Rivoire, Miettinen \& Spirin) from the old continent have been described recently on rare occasions (Kotiranta et al. 2017, Miettinen et al. 2016) and new occurrences of extra-European (i.e. tropical or subtropical) polypores have also been reported sporadically, e.g. Amylosporus campbellii (Berk.) Ryvarden (Bernicchia et al. 2017). In 2016, a peculiar polyporoid species was found in Hungary (Central Europe) on the trunk of a planted hackberry tree (Celtis sp.). Macroscopically the basidiome is related to the favoloid morphotypes of Polyporus s. lato, but it differs from any known European species, viz. Favolus pseudobetulinus (Murashk. ex Pilát) Sotome \& T. Hatt and Neofavolus alveolaris (DC.) Sotome \& T. Hatt.

The sanctioned genus Favolus Fr. (non Favolus P. Beauv.) was established by Fries (1828) and later F. brasiliensis (Fr.) Fr. (三Daedalea brasiliensis Fr.) was selected as a generic type (Donk 1960). In their monographic study, Núñez \& Ryvarden (1995) treated "Favolus" as one of the six infrageneric groups of the genus Polyporus P. Micheli ex Adans., and characterized by the flabelliform to dimidiate pileus and the short lateral stipe without a dark crust. They listed four species to the "Favolus" group, namely Polyporus alveolaris (DC.) Bondartsev \& Singer, $P$. grammocephalus Berk., P. philippinensis Berk., and P. tenuiculus (P. Beauv.) Fr. (as a synonym of Favolus brasiliensis).

Table 1 Species, specimens and sequences used in the phylogenetic analysis. 


\begin{tabular}{|c|c|c|c|c|}
\hline Species name & Sample no. & Locality & ITS & References \\
\hline Favolus acervatus & MEL:2382618 & Australia & KP012981 & GenBank \\
\hline F. acervatus & Cui11053 & China & KU189774 & Zhou et al. (2016) \\
\hline F. acervatus & SFC20120725-05 & Korea & KX792916 & Kim et al. (2016) \\
\hline F. acervatus & TFM:F-14764 & Japan & AB735971 & Sotome et al. (2013) \\
\hline F. brasiliensis & TENN10242 & Costa Rica & AB735976 & Sotome et al. (2013) \\
\hline F. brasiliensis & INPA:241452 & Brazil & AB735977 & Sotome et al. (2013) \\
\hline F. emerici & MEL:2382691 & Australia & KP013055 & GenBank \\
\hline F. emerici & Dai 7847 & China & KM385430 & GenBank \\
\hline F. gracilisporus ${ }^{\mathrm{a}}$ & SFC20130704-40 & $\begin{array}{l}\text { South } \\
\text { Korea }\end{array}$ & KY038472 & Tibpromma et al. (2017) \\
\hline F. gracilisporus $^{\mathrm{a}}$ & LWZ 20130809-15 & China & KM385429 & GenBank \\
\hline F. gracilisporus & BP 106942 & Hungary & MF401551 & In this study \\
\hline F. grammocephalus $^{\mathrm{b}}$ & WD2379 & Japan & AB587628 & Sotome et al. (2011) \\
\hline F. grammocephalus & Cui10926 & China & KU189776 & Zhou et al. (2016) \\
\hline F. philippinensis ${ }^{\mathrm{b}}$ & Cui10941 & China & KX548976 & GenBank \\
\hline F. philippinensis ${ }^{\mathrm{b}}$ & Dai7959 & China & KX548977 & GenBank \\
\hline F. philippinensis ${ }^{\mathrm{b}}$ & Dai10849 & China & KX548978 & GenBank \\
\hline F. pseudobetulinus ${ }^{\mathrm{b}}$ & CulTENN10298 & Finland & AF516571 & Krüger (2002) \\
\hline F. pseudobetulinus ${ }^{\mathrm{b}}$ & TRTC:51022 & Canada & AB587629 & Sotome et al. (2011) \\
\hline F. pseudobetulinus ${ }^{\mathrm{b}}$ & TFM:F-27626 & Japan & AB587645 & Sotome et al. (2011) \\
\hline F. roseus & UOC WASNP W13 & Sri Lanka & KR049231 & GenBank \\
\hline F. roseus & IJV04 & Tanzania & KM593876 & Juma et al. (2016) \\
\hline F. tenuiculus & Dai13615A & China & KU189775 & Zhou et al. (2016) \\
\hline F.tenuiculus ${ }^{\mathrm{b}}$ & ML284 & Malaysia & JQ409357 & GenBank \\
\hline F. tenuiculus ${ }^{\mathrm{b}}$ & Mu_1 & unknown & КС951263 & GenBank \\
\hline F. tenuiculus ${ }^{\mathrm{b}}$ & HE'2934 & unknown & KC505555 & GenBank \\
\hline Neofavolus alveolaris & KUC20130808-54 & $\begin{array}{l}\text { South } \\
\text { Korea }\end{array}$ & KJ668478 & Jang et al. (2015) \\
\hline N. mikawai & TFM:F-27416 & Japan & AB735962 & Sotome et al. (2013) \\
\hline N.cremeoalbidus & TUMH:50009 & Japan & AB735980 & Sotome et al. (2013) \\
\hline
\end{tabular}

Notes: new sequence is in bold.

${ }^{\text {a }}$ as Favolus sp. in GenBank.

${ }^{\mathrm{b}}$ as Polyporus in GenBank.

The phylogenetic analyses proved by Sotome et al. (2013) reveal that the infrageneric group "Favolus" is divided into two main clades in generic level. Based on morphological observations and molecular phylogenetic evidence, they revised Favolus and proposed Neofavolus Sotome \& T. Hatt. as a new genus, typified on $N$. alveolaris. In this study we aimed to clarify the species level identity of the Hungarian "favoloid" specimen, based on macro- and micro-morphological features and molecular phylogenetic analysis of the ITS region.

\section{Materials \& Methods}

\section{Isolates and morphology}

The Hungarian specimen studied is deposited at the herbarium of Hungarian Natural History Museum (BP). Macromorphological descriptions are based on field notes. Micromorphological data were obtained from the dried specimens, and observed under a Zeiss Axio Imager.A2 light microscope, equipped with AxioVision Release 4.8.2. software. Measurements were done with a $100 \times$ oil immersion objective (1000x magnification). Drawings were produced with the aid of a drawing tube. Observations of microscopic features as well as measurements, and drawings were made from slide preparations stained with Melzer's reagent. Spores were measured from sections cut from the tubes. The following abbreviations were used in the description of the basidiospores: IKI = 
Melzer's reagent, IKI- $=$ both inamyloid and indextrinoid, $\mathrm{L}=$ mean spore length, $\mathrm{W}=$ mean spore width, $\mathrm{Q}=$ variation in the $\mathrm{L} / \mathrm{W}$ ratios, $\mathrm{n}=$ number of spores were measured.

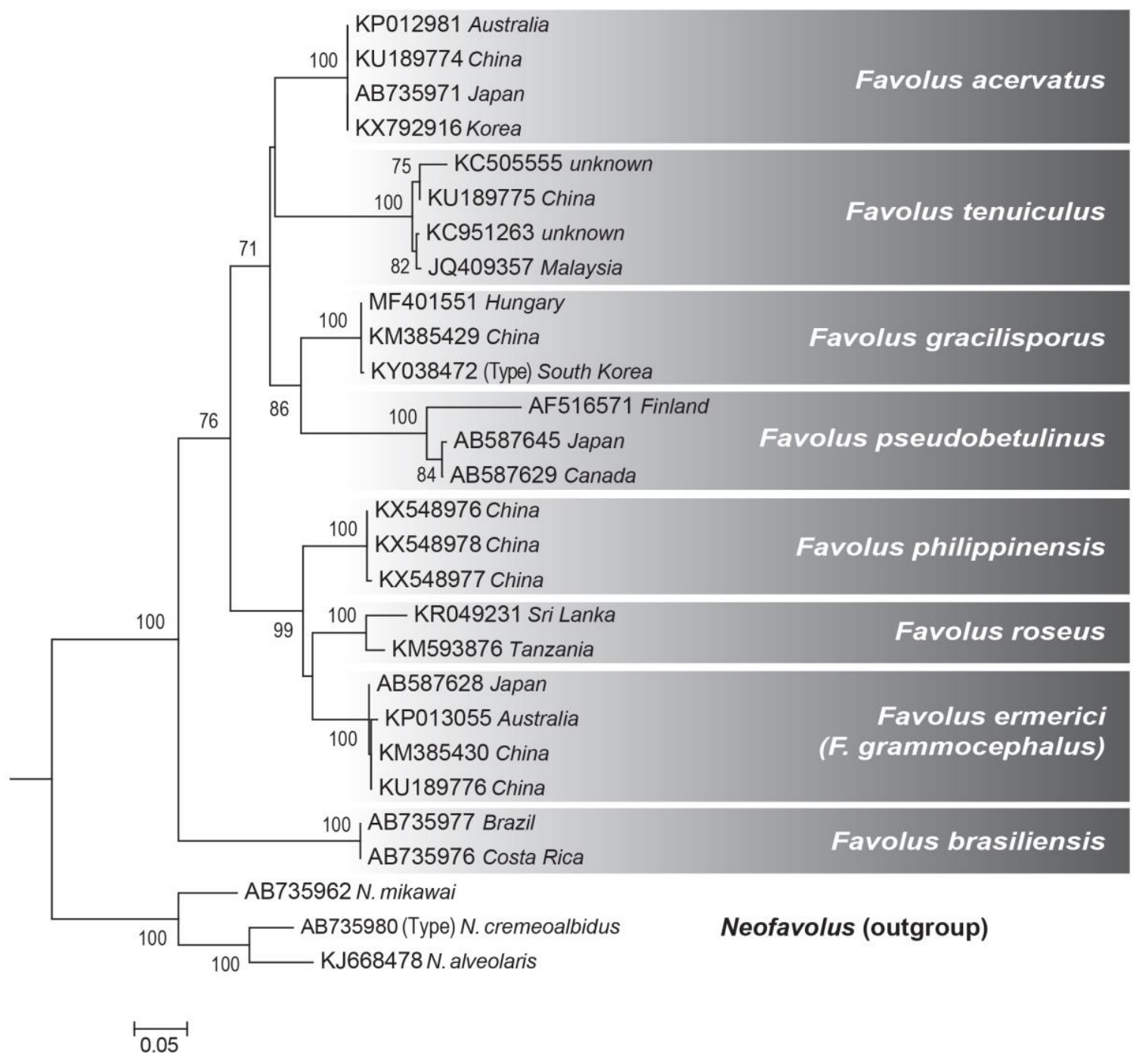

Figure 1 - Phylogenetic tree obtained from ITS sequences. Maximum likelihood bootstrap values $>70 \%$ are given at the branches. Bar indicates 0.05 expected change per site per branch.

\section{DNA isolation and PCR Analysis}

We generated data for the ITS (internal transcribed spacer) nrDNA regions using the Phire ${ }^{\circledR}$ Plant Direct PCR Kit (Thermo Scientific, USA) and following the manufacturer's recommendations. The primer pairs ITS1F/ITS4 (Gardes \& Bruns 1993, White et al. 1990) were used to amplify the ITS regions. PCR procedures were as follows: initial denaturation on $98{ }^{\circ} \mathrm{C}$ for $5 \mathrm{~min}$, followed by 40 cycles denaturation on $98^{\circ} \mathrm{C}$ for $5 \mathrm{~s}$, annealing on $55^{\circ} \mathrm{C}$ for $5 \mathrm{~s}$, extension on $72{ }^{\circ} \mathrm{C}$ for $5 \mathrm{~s}$, and a final extension on $72{ }^{\circ} \mathrm{C}$ for $1 \mathrm{~min}$. PCR products were checked in $2 \%$ agarose gels. The amplicons were sequenced commercially at LGC Genomics (Berlin, Germany) with the same primers used in PCR reactions. The chromatograms were checked, assembled and edited with the CodonCodeAligner 7.0.1 (CodonCode Corporation, Centerville, MA, USA).

\section{Sequence alignment and phylogenetic analysis}

The newly generated Favolus sequence is deposited in GenBank (Benson et al. 2017) and the accession numbers is included in Table 1. For the phylogenetic analysis, similar sequences were searched from GenBank using the BLASTn search tool (Altschul et al. 1990). The ITS region was aligned with PRANK (Löytynoja \& Goldman 2005, 2008) as implemented in its graphical interface (PRANKSTER) using default settings. SeaView (Gouy et al. 2010) was used to visually inspect and 
improve the alignment. Gaps were coded following the simple indel coding algorithm (Simmons et al. 2001) with the program FastGap 1.2 (Borchsenius 2009). The nucleotide and the binary data sets resulted an alignment length of 773 characters. Maximum Likelihood (ML) phylogenetic analysis was carried out using RAxML (Stamatakis 2014) in raxmlGUI (Silvestro \& Michalak 2012). For the nucleotide partition the GTRGAMMA substitution model, while for the indel partition the RAxML default set for binary characters were applied. Rapid bootstrap analysis with 1,000 replicates was performed using sequences of the genus Neofavolus as outgroup. The alignment and phylogenetic tree is deposited in TreeBASE under S21252.

\section{Results}

\section{ITS sequence analyses}

Altogether 25 ITS sequences of Favolus were included in our ML phylogenetic analysis. Eight strongly supported species level clades were recognized. The Hungarian specimen (MF401551) clustered together with Favolus sp. collected in China (KM385429) and the holotype of $F$. gracilisporus H. Lee, N.K. Kim \& Y.W. Lim (KY038472), which is a recently described species from South Korea (Tibpromma et al. 2017). The closest species based on our ITS analysis is $F$. pseudobetulinus with only $89 \%$ identity (564/636). Other morphologically somewhat similar species, i.e. F. emerici (Berk. ex Cooke) Imazeki, F. philippinensis (Berk.) Sacc. and F. roseus Lloyd cluster in a separate, strongly supported clade (BS=99\%).

\section{Taxonomy}

Favolus gracilisporus H. Lee, N.K. Kim \& Y.W. Lim, in Tibpromma et al., Fungal Diversity 83: 219, 2017.

Basidiomes annual, attached by a short, rounded and undifferentiated lateral stipe, solitary or several form a branched base; pilei flabelliform to circular, up to $60 \mathrm{~mm}$ from the base to margin, up to $110 \mathrm{~mm}$ in width and $7 \mathrm{~mm}$ thick; upper surface azonate, fibrillose, radially striate, ivory to pale buff; margin concolorous or darker with age; hymenophore poroid, whitish or cream to pale brown, pores radially elongated, $2-2.5 \mathrm{~mm}$ long and $0.5-1 \mathrm{~mm}$ wide; dissepiments entire to slightly lacerate; tubes pale tan to ivory, corky, brittle when dry, up to $0.7 \mathrm{~mm}$ thick; context concolorous, continuous with the tube, homogenous, up to $5.5 \mathrm{~mm}$ thick. Stipe short, laterally attached to the pileus, buff, glabrous, with decurrent pores. Hyphal system dimitic with generative hyphae and skeleto-binding hyphae; generative hyphae hyaline in $\mathrm{KOH}$, thin-walled, 3-4 $\mu \mathrm{m}$ in diam., septa with clamps, the thick-walled skeleto-binding hyphae aseptate, much branched, dominating in the basidiocarp, 3-6 $\mu \mathrm{m}$ in diam. Cystidia and cystidioles absent. Basidia clavate, 4-sterigmate, difficult to observe, 19$23 \times 5-6 \mu \mathrm{m}$, with a basal clamp connection. Basidiospores cylindric to slightly allantoid, hyaline, smooth, IKI-, (7.40-)7.72-8.38(-8.76) ×(3.14-)3.27-3.5(-3.69) $\mu \mathrm{m}, \mathrm{L}=8.1 \mu \mathrm{m}, \mathrm{W}=3.3 \mu \mathrm{m}, \mathrm{Q}=$ $2.39(\mathrm{n}=30)$.

Specimen examined - Hungary, Central Transdanubia, Komárom-Esztergom County, Komárom (N 4743'15", E 188'37"), leg. P. Jakab, 27 May 2016, on Celtis sp. trunk (BP 106942).

\section{Discussion}

Several recent phylogenetic studies confirmed that Polyporus is a polyphyletic genus, and treated Favolus and Neofavolus as separate genera (e.g. Dai et al. 2014, Seelan et al. 2015, Sotome et al. 2013, Zhou et al. 2016, Zmitrovich \& Kovalenko 2016). The genus Neofavolus comprises four species, out of which the subporoid lamellae forming N. suavissimus (Fr.) J.S. Seelan, Justo \& Hibbett (Seelan et al. 2015) and N. alveolaris have been found in Europe (Ryvarden \& Melo 2014). Neofavolus alveolaris has similar diamond-shaped pores and a laterally stipitate basidiocarp as Favolus gracilisporus, but it can be distinguished by the solitary, typically smaller basidiocarp which has orange-yellow pileus with brown triangular squamules when young, as well as the larger basidiospores [10-13(-14.5) $\times(3.5-) 4-5 \mu \mathrm{m}]$ measured in European specimens, and the preference 
of growing on small branches of different deciduous trees (Bernicchia 2005, Piątek 2004, Ryvarden \& Melo 2014).
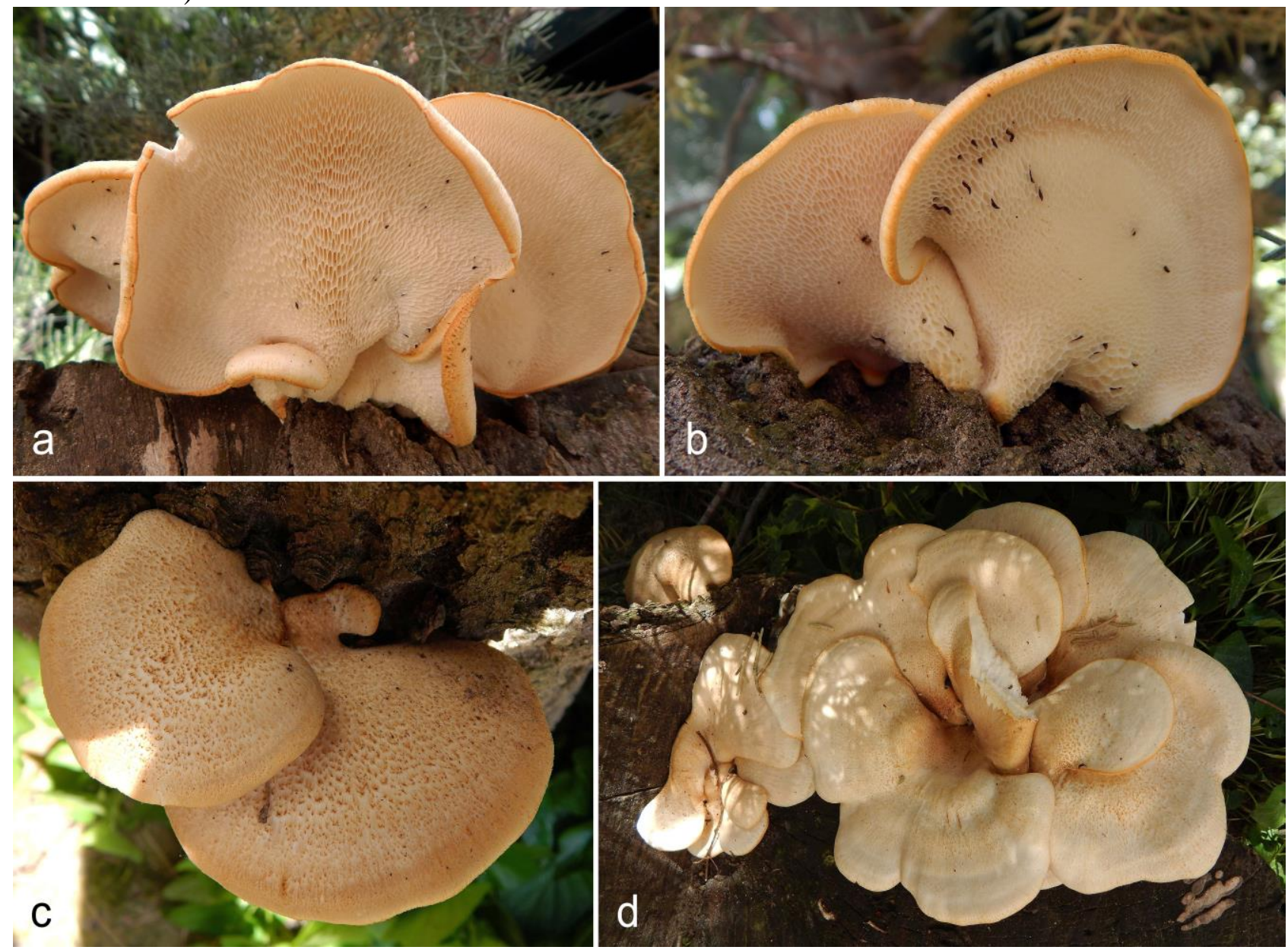

Figure 2 - Favolus gracilisporus basidiomes in the habitat (BP 106942). a-b pore surface. c-d pileal surface. Photographs by György Vrba

Most of the species accepted in the genus Favolus s. str. are mainly distributed in tropical areas (Sotome et al. 2013), and only F. pseudobetulinus is known from Europe, with a boreal distribution (Ryvarden \& Melo 2014, Dai 2012). This species is closely related to F. gracilisporus in the phylogenetic analysis based on ITS sequences, but it has smaller angular pores (1-2 per mm) and simple septate tramal generative hyphae (Sotome et al. 2011). Favolus roseus distributed in tropical areas of Southeast Asia has similar radially elongated pores $(1-3 \times 0.5-2 \mathrm{~mm})$ as $F$. gracilisporus, but it differs by the small basidiocarps with yellowish to brownish orange pore surface (Sotome et al. 2013). Favolus elongoporus (Drechsler-Santos \& Ryvarden) Zmitr. \& Kovalenko was described from Brazil that also has large irregularly elongated pores $(0.5-2$ per $\mathrm{mm}$ radially), but the hyphal pegs, the arboriform binding hyphae and the distinctly smaller basidia $(10-15 \times 3-7 \mu \mathrm{m})$ and basidiospores $(6-8 \times 2-3 \mu \mathrm{m})$ distinguished it from F. gracilisporus (Drechsler-Santos et al. 2008). Based on the morphological study of the holotype of $F$. philippinenis, Sotome et al. (2013) noted that this species is characterized by the large angular and elongated pores (1-4 mm long and $0.5-1.5 \mathrm{~mm}$ wide), the brownish orange pileus and the leathery context. Favolus philippinensis is widely accepted as a separate species (Coelho \& da Silveira 2014, Gomes-Silva et al. 2012, Louza \& Gugliota 2007, Sotome et al. 2013, Silveira \& Wright 2002) and it has several synonyms as well proposed by Ryvarden (1989) based on type studies of the favoloid species described by Hennings (1900) and Lloyd (1922, 1923) from Southeast Asia and Oceania (i.e. F. glandulosus Lloyd, F. lagunae Lloyd, F. samoensis Lloyd, F. scabrolineatus Lloyd and Polyporus tomohoniensis Henn.), although, these synonymizations lack molecular phylogenetic investigations. 


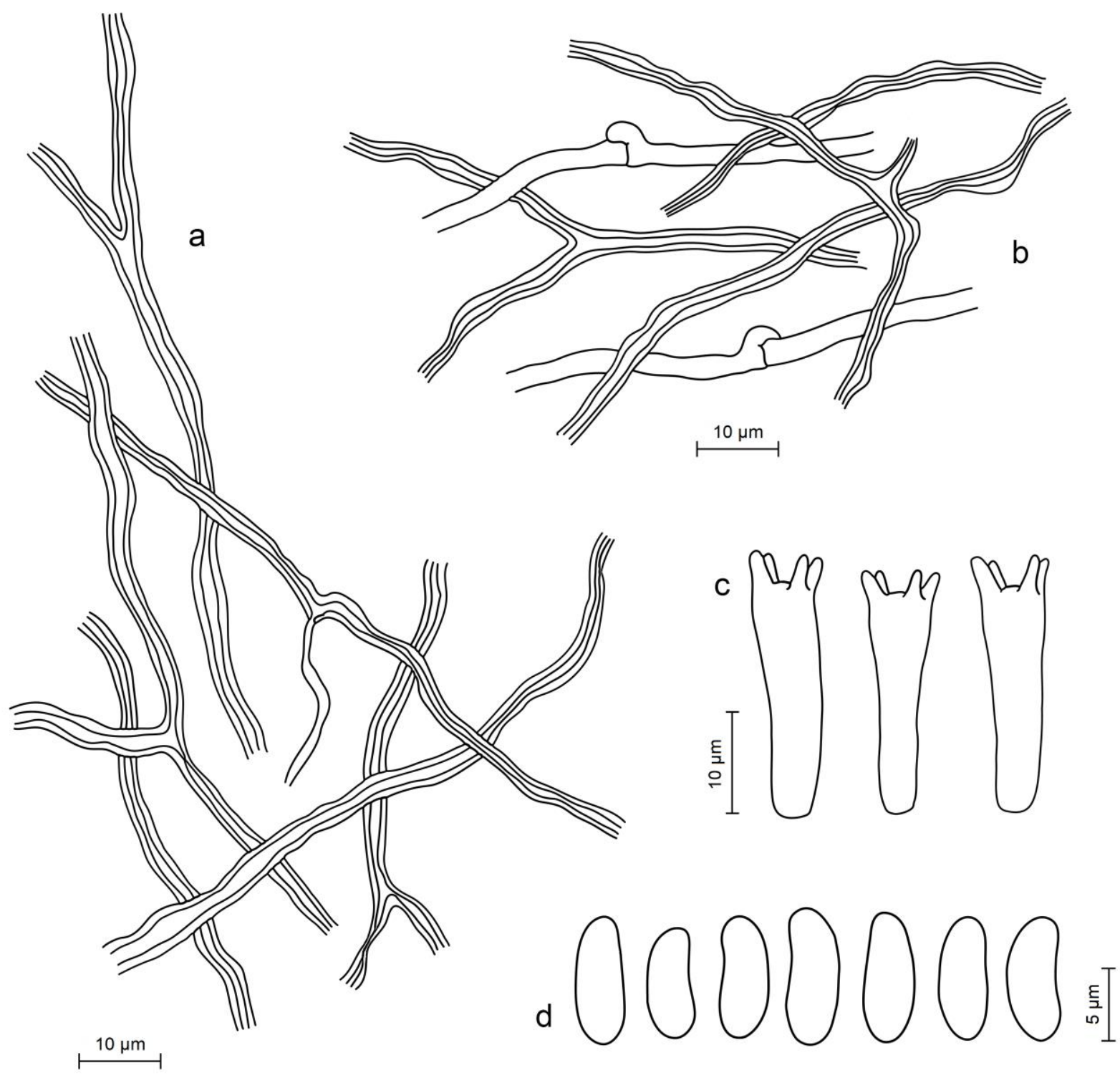

Figure 3 - Microscopic structure of Favolus gracilisporus (BP 106942). a contextual skeletalbinding hyphae. $\mathrm{b}$ clamped generative hyphae and skeletal-binding hyphae in the trama. $\mathrm{c}$ basidia. $\mathrm{d}$ basidiospores.

\section{Conclusion}

Molecular data confirm that the collection from Hungary is identical with the holotype of Favolus gracilisporus, although according to the description proved by Tibpromma et al. (2017) the Korean specimen has somewhat larger spores $(7.9-9.7 \times 2.5-3.3 \mu \mathrm{m})$ and basidia $(27-35 \times 5.7-8$ $\mu \mathrm{m}$ ) and distinctly thinner basidiocarp (up to $3.5 \mathrm{~mm}$ ). The study of more collections of this species is needed to better estimate the morphological variability and real distribution of this taxon. Several species classified in Favolus by morphological features have not been studied by molecular methods (e.g. Zmitrovich \& Kovalenko 2016) and a robust phylogeny including more specimens (e.g. type specimens) and species are needed to estimate a better knowledge of the genus. According to the present knowledge, F. gracilisporus is a separate species in the genus Favolus and the Hungarian findings is a new representative of this species to the European mycobiota.

\section{Acknowledgements}

The authors are grateful to György Vrba for providing us the specimen and his in situ photos of the basidiocarps. We thank the anonymous reviewers for their useful comments and suggestions. 


\section{References}

Altschul SF, Gish W, Miller W, Myers EW, Lipman DJ. 1990 - Basic local alignment search tool. Journal of Molecular Biology 215, 403-410.

Benson DA, Cavanaugh M, Clark K, Karsch-Mizrachi I, Lipman DJ, Ostell J, Sayers EW. 2017 - GenBank. Nucleic Acids Research 45(D1), D37-D42.

Bernicchia A, Genovese R, Gorjón SP 2017 - Amylosporus campbellii (Berk.) Ryvarden (Bondarzewiaceae, Basidiomycota), new record to Europe. Mycosphere 8(1), 98-101.

Bernicchia A. 2005 - Polyporaceae s. 1. In: Fungi Europaei, vol. 10, Alassio. 808 p.

Borchsenius F. 2009 - FastGap 1.2. http://www.aubot.dk/FastGap_home.htm, Department of Biosciences, Aarhus University, Denmark.

Coelho G, da Silveira RMB 2014 - Taxonomy of Polyporus sensu lato and related genera (Basidiomycota) from Santa Maria, southern Brazil. Ciência e Natura, Santa Maria, 36(II), 688-710.

Dai YC, Xue HJ, Vlasák J, Rajchenberg M, Wang B, Zhou LW. 2014 - Phylogeny and global diversity of Polyporus group Melanopus (Polyporales, Basidiomycota). Fungal Diversity 64, 133-144.

Dai YC. 2012 - Polypore diversity in China with an annotated checklist of Chinese polypores. Mycoscience $53,49-80$.

Donk MA. 1960 - The generic names proposed for Polyporaceae. Persoonia 1(2), 173-302.

Drechsler-Santos ER, Ryvarden L, Wartchow F, Cavalcanti MAQ. 2008 - Polyporus elongoporus (Aphyllophorales, Poriaceae) sp. nov. Synopsis Fungorum 25, 38-43.

Fries EM. 1828 - Elenchus Fungorum. Vol. 1. Gryphiswaldiae. 238 pp.

Gardes M, Bruns TD. 1993 - ITS primers with enhanced specificity for basidiomycetes - application to the identification of mycorrhizae and rusts. Molecular Ecology 2(2), 113-118.

Gomes-Silva AC, Ryvarden L, Medeiros PS, Pontes Sotão HM \& Gibertoni TB 2012 - Polyporus (Basidiomycota) in the Brazilian Amazonia, with notes on Polyporus indigenus I.J. Araujo \& M.A. de Sousa and P. sapurema A. Møller. Nova Hedwigia 94, 227-238.

Gouy M, Guindon S, Gascuel O. 2010 - SeaView version 4: a multiplatform graphical user interface for sequence alignment and phylogenetic tree building. Molecular Biology \& Evolution 27(2), 221-224.

Hennings P. 1900 - Fungi monsunenses. Monsunia 1, 137-174.

Jang Y, Jang S, Min M, Hong JH, Lee H, Lee H, Lim YW, Kim JJ. 2015 - Comparison of the diversity of basidiomycetes from dead wood of the manchurian fir (Abies holophylla) as evaluated by fruiting body collection, mycelial isolation, and 454 sequencing. Microbial Ecology 70(3), 634-645.

Juma I, Mshandete AM, Tibuhwa DD, Kivaisi AK. 2016 - Identification of Tanzanian saprophytic edible mushrooms by amplification and sequencing of ITS/LSU regions of ribosomal RNA operon. Tanzania Journal of Science 42, 109-121.

Kim NK, Park JY, Park MS, Lee H, Cho HJ, Eimes JA, Kim C, Lim YW. 2016 - Five new wood decay fungi (Polyporales and Hymenochaetales) in Korea. Mycobiology 44(3), 146-154.

Kotiranta H, Kulju M, Miettinen O. 2017 - Caudicicola gracilis (Polyporales, Basidiomycota), a new polypore species and genus from Finland. Annales Botanici Fennici 54: 159-167.

Krüger D. 2002 - Monographic studies in the genus Polyporus (Basidiomycotina). Doctoral dissertation. University of Tennessee, Knoxville.

Lloyd CG. 1922 - Mycological Notes 67. Mycological Writings 7(67), 1137-1168.

Lloyd CG. 1923 - Mycological Notes 69. Mycological Writings 7(69): 1185-1218.

Louza GSG, Gugliotta AM. 2007 - Polyporus Fr. (Polyporaceae) no Parque Estadual das Fontes do Ipiranga, São Paulo, SP, Brasil. Hoehnea 34(3), 365-382.

Löytynoja A, Goldman N. 2005 - An algorithm for progressive multiple alignment of sequences with insertions. Proceedings of the National Academy of Sciences of the U.S.A. 102(30), 10557-10562.

Löytynoja A, Goldman N. 2008 - Phylogeny-aware gap placement prevents errors in sequence alignment and evolutionary analysis. Science 320, 1632-1635.

Miettinen O, Spirin V, Vlasák J, Rivoire B, Stenroos S, Hibbett D. 2016 - Polypores and genus concepts in Phanerochaetaceae (Polyporales, Basidiomycota). Mycokeys 17, 1-46.

Núñez M, Ryvarden L. 1995 - Polyporus (Basidiomycotina) and related genera. Synopsis Fungorum 10, 185.

Piątek M. 2004 - Notes on Polish polypores 4. Polyporus alveolaris. Karstenia 44, 61-66.

Ryvarden L, Melo I. 2014 - Poroid fungi of Europe. Synopsis Fungorum 31, 1-455.

Ryvarden L. 1989 - Type studies in the Polyporaceae 21. Species described by C.G. Lloyd in Cyclomyces, Daedalea, Favolus, Fomes and Hexagonia. Mycotaxon 35: 229-236. 
Seelan JSS, Justo A, Nagy LG, Grand EA, Redhead SA, Hibbett D. 2015 - Phylogenetic relationships and morphological evolution in Lentinus, Polyporellus and Neofavolus, emphasizing southeastern Asian taxa. Mycologia 107, 460-474.

Silveira RMB, Wright JE. 2002 - Polyporus s. str. In southern South America: mating tests. Mycological Research 106, 1323-1330.

Silvestro D, Michalak I. 2012 - raxmlGUI: a graphical front-end for RAxML. Organisms Diversity \& Evolution 12, 335-337.

Simmons MP, Ochoterena H, Carr TG. 2001 - Incorporation, relative homoplasy, and effect of gap characters in sequence-based phylogenetic analysis. Systematic Biology 50(3), 454-462.

Sotome K, Akagi Y, Lee SS, Ishikawa NK, Hattori T. 2013 - Taxonomic study of Favolus and Neofavolus gen. nov. segregated from Polyporus (Basidiomycota, Polyporales). Fungal Diversity 58, 245-266.

Sotome K, Hattori T, Ota Y. 2011 - Taxonomic study on a threatened polypore, Polyporus pseudobetulinus, and a morphologically similar species, P. subvarius. Mycoscience 52: 319-326.

Stamatakis A. 2014 - RAxML version 8: a tool phylogenetic analysis and post-analysis of large phylogenies. Bioinformatics 30, 1312-1313

Tibpromma S, Hyde KD, Jeewon R et al. 2017 - Fungal diversity notes 491-602: taxonomic and phylogenetic contributions to fungal taxa. Fungal Diversity 83(1), 1-261.

White TJ, Bruns T, Lee S, Taylor J. 1990 - Amplification and direct sequencing of fungal ribosomal RNA genes for phylogenetics. In: Innis MA, Gelfand DH, Sninsky JJ, White TJ. (eds) PCR protocols: a guide to methods and applications. Academic Press, New York, pp 315-32.

Zhou JL, Zhu L, Chen H, Cui BK. 2016 - Taxonomy and phylogeny of Polyporus group Melanopus (Polyporales, Basidiomycota) from China. PLoS ONE 11(8), e0159495.

Zmitrovich IV, Kovalenko AE. 2016 - Lentinoid and polyporoid fungi, two generic conglomerates containing important medicinal mushrooms in molecular perspective. International Jouranl of Medicinal Mushrooms 18(1), 23-38. 